University of Texas Rio Grande Valley

ScholarWorks @ UTRGV

8-24-2018

\title{
Synergy between Green Supply Chain Management and Green Information Systems on Corporate Sustainability: An Informal Alignment Perspective
}

\author{
Zhaojun Yang \\ Xidian University \\ Jun Sun \\ The University of Texas Rio Grande Valley, jun.sun@utrgv.edu \\ Yali Zhang \\ Northwestern Polytechnical University \\ Ying Wang \\ The University of Texas Rio Grande Valley
}

Follow this and additional works at: https://scholarworks.utrgv.edu/is_fac

Part of the Management Information Systems Commons

\section{Recommended Citation}

Yang, Z., Sun, J., Zhang, Y. et al. Synergy between green supply chain management and green information systems on corporate sustainability: an informal alignment perspective. Environ Dev Sustain 22, 1165-1186 (2020). https://doi.org/10.1007/s10668-018-0241-9

This Article is brought to you for free and open access by the Robert C. Vackar College of Business \& Entrepreneurship at ScholarWorks @ UTRGV. It has been accepted for inclusion in Information Systems Faculty Publications and Presentations by an authorized administrator of ScholarWorks @ UTRGV. For more information, please contact justin.white@utrgv.edu,william.flores01@utrgv.edu. 


\title{
Synergy between Green Supply Chain Management and Green Information Systems on Corporate Sustainability: An Informal Alignment Perspective
}

\begin{abstract}
At the corporate level, green innovation is essential for environment protection and sustainable development. Green supply chain management (GSCM) and green information system (GIS) are two important pillars of green innovation. This study investigates the possible alignment between them in terms of the synergistic effect on corporate sustainability. Based on the task-technology fit model, GSCM and GIS can be viewed as the task- and technology-side endeavors. The extant conceptualization the fit between a task and a technology assumes their interdependence, yet efficiency-oriented GSCM and technology-driven GIS are relatively independent from each other as they can be carried out separately. Formed on the basis of spontaneous employee participation in both, their alignment is rather informal than formal. Unlike the regular task-technology fit from a top-down arrangement, such a bottom-up alignment is not the necessary condition for GSCM and GIS to take effects, but adds to their direct impacts on green innovation outcome in a one-plus-one-greater-than-two manner. Survey observations gathered from over 300 organizations in China confirm that the informal alignment between GSCM and GIS enhances economic, operational, environmental and social performances on top of their primary contributions. The synergy between GSCM and GIS on corporate sustainability provides researchers and practitioners helpful insights on how to optimize green innovation effectiveness.
\end{abstract}

Keywords: Green Supply Chain Management; Green Information Systems; Informal Alignment; Green Innovation; Corporate Sustainability.

\section{Introduction}

Sustainable development, "a development that meets the needs of the present without compromising the ability of future generations to meet their own needs" (Brundtland 1987), has become a major concern of modern societies. Corporates may fulfill their social responsibility by making their production and operation environment friendly (Andersen and Skjoett-Larsen 2009). Such organizational endeavors can be categorized under the umbrella term of "green (or eco) innovation" pertaining to "the creation or implementation of new, or significantly improved, products (goods and services), processes, marketing methods, organizational structures and institutional arrangements which - with or without intent - lead to environmental improvements compared to relevant alternatives" (OECD 2010). Except for some organizations that intentionally pursue environmental goals for green image or reputation, most green innovation endeavors are pulled by the efficiency demand or pushed by technology advancement for competitive advantages (Testa and Iraldo 2010).

At the start, green innovation endeavors are mostly efficiency-oriented, as represented by green supply chain management (GSCM) that aims to conserve resources and reduce emissions in production and distribution processes (Rao and Holt 2005; Porter and Kramer 2006). To maximize and retain the efficiency gain, many organizations further resort to the advancement in information technology, leading to more technology-driven green innovation activities (Chiabai et al. 2013). Whereas the term "green information technology (GIT)" has been primarily associated with the energy consumption of computer chips, servers, hardware devices, and data centers (Murugesan 2008), the concept of "green information systems (GIS)" concerns the establishment of systems and practices to support organizational operations for sustainable development (Dedrick 2010).

Separately, researchers examine how GSCM or GIS affect organizational performances. For instance, it is recognized that GSCM may significantly improve environmental performance, corporate image and competitive advantage (Rao and Holt 2005; Chiou et al. 2011; Zhu et al. 2012). Meanwhile, the relationship between GIS and sustainable development increasingly draws researchers' attention (Watson et al. 2010). However, few studies investigate how GIS and GSCM together influence the outcome of green innovation from the alignment perspective. This is probably due to the fact that the two endeavors are relatively independent from each other, whereas most alignment conceptualizations are based on the premise of inter-dependence, such as task-technology fit and strategystructure alignment (Goodhue and Thompson 1995; Jordan and Tricker 1995).

In most organizations, different departments and functionalities are in charge of GSCM and GIS. Yet, it is possible to coordinate the effort on different endeavors to maximize their effectiveness for the same purpose. For 
instance, enterprises like Wal-Mart centralized IT infrastructure with virtualization and data warehousing technologies to save resources, which was found helpful in streamlining supply chain management as well (Boudreau et al. 2008). In daily operations, employees often carry out managerial and technological activities together, leading to a one-plus-one-greater-than-two effect on performances. Likewise, their engagement in GSCM and GIS endeavors may yield a synergy on corporate sustainability, and such an alignment is rather informal as one does not depend on the other.

There is a lack of theoretical discussion and empirical analysis on this emerging form of alignment, and this study attempts to examine GSCM-GIS fit in terms of its formation and consequence. It conceptualizes that the spontaneous participation of employees in both green innovation endeavors lead to their bottom-up alignment in contrast to the regular top-down task-technology fit, and develops a research model accordingly. Survey observations were collected from the managers of various organizations to find out whether such an alignment makes an additional contribution to corporate sustainability on top of GSCM and GIS. The findings may shed light on the best practices of green innovation, especially how to maximize the effectiveness of GSCM and GIS.

\section{Research Background}

As an efficiency-oriented green innovation endeavor from the beginning, GSCM aims to reengineer the supply chain management of an organization in order to optimize resource utilization and reduce environmental footprints (Min and Galle 1997; Zsidisin and Siferd 2001). The implementation is often extended beyond internal operations to external cooperation with upstream suppliers and downstream customers (Seuring and Müller 2008). Thus, GSCM enhances corporate sustainability comprehensively in procurement, production, distribution and recycling (Srivastava 2007; Muduli and Barve 2013). Earlier studies primarily focused on the implementation of GSCM, such as top management support, cross-department cooperation, and collaboration among upstream and downstream enterprises (Vachon and Klassen 2006). In recent years, researchers pay more attention to the impacts of GSCM on organizational performances, especially from the economic and environmental aspects (Zhu et al. 2007; Green Jr et al. 2012; Tseng and Chiu 2013).

Green innovation has also been driven by the advancement in information and communication technologies (Ozturk et al. 2011). Even before the environmental movement, researchers have recognized the critical role of information systems to facilitate information flow in supply chain management (Legarth 2001; Darnall et al. 2008). The emerging GIS functionalities provide more direct support to corporate sustainability by enhancing the environmental effectiveness of business routines (Chofreh et al. 2014). There are designated environmental management systems for energy conservation and pollution control, as well as more general systems like groupware and electronic workflow for travel reduction and paperless operation (Melville 2010). Compared with the traditional supportive role of IT, GIS has profound impacts on organizational operation, management and strategy, such as project teamwork, customer outreach, and partner cooperation (Chen et al. 2011; Loos et al. 2011).

The fact that GSCM and GIS endeavors can be carried out independently makes their possible alignment somewhat unique. The concept of alignment is rooted in the field of management to investigate such phenomena as strategy-structure fit: organizations that adapt their structures to business strategies are more likely to survive the competitive environment and prosper (Jordan and Tricker 1995; Grøgaard 2012). Information system researchers derive the construct of task-technology fit based on the premise that when system characteristics meet task requirements, user engagement and performance are enhanced (Goodhue and Thompson 1995; Lin and Huang 2008). Although the original level of analysis is individual, many organization-level studies on task-technology fit involve corporate endeavors and enterprise systems (Dymoke-Bradshaw and Cox 2005; Strong and Volkoff 2010; Fuller and Dennis 2009).

Due to their different orientations, GSCM and GIS can be regarded as the task-side and technology-side of green innovation, and it seems logical to treat their possible alignment as task-technology fit. The extant conceptualization, however, is based on the premise that task accomplishment relies on technology use (e.g. inventory management systems, accounting information systems). The formation of such an alignment pertains to how well organizations implement systems so that employees can use them effectively in their jobs. Compared with such a formal alignment as the result of a top-down arrangement, the alignment between GSCM and GIS is rather informal as they are relatively independent (e.g. an organization can implement one without the other). Yet, once employees have the chance to participate in both green innovation endeavors, they may find it natural to combine the efforts that share commonalities for the same purpose. 
Primary GSCM activities comprise eco design, supply chain processes, internal environmental management (Lee et al. 2012; Zhu and Sarkis 2006), and GIS activities mainly include pollution prevention, product stewardship, and sustainable development (Daugherty et al. 2005; Gholami et al. 2013). Underlying the activities are common dimensions related to the goal, process, and support concerning technology-enabled business innovation (Davenport 2013). GSCM-side eco design and GIS-side pollution prevention directly target the ecological goal, supply chain processes and product stewardship involve the business process leading to the end, and internal environmental management and sustainable development provide organizational support (e.g. management, policy and culture). When employees engage in both GSCM and GIS activities, they are likely to make consistent and complementary efforts along the goal, process, and structure dimensions, leading to the informal alignment between the task and technology sides of green innovation.

Though there is a lack of discussion on informal alignment, researchers take note of the natural and spontaneous involvement of employees in different activities concerning the allocation and utilization of organizational resources beyond strategic planning (Guth and MacMillan 1986). The discussions lead to the rethinking of alignment concept from a top-down perspective to a bottom-up perspective in the fields of green strategies as well as information system strategies (Leidner et al. 2017; Roettgers 2011). In bottom-up organizational changes, middle management provides critical employee support through coordinating collective efforts and allocating needed resources (Heyden et al. 2017). When employees experience ineffectiveness from the unbalanced development of GSCM and GIS, managers may communicate their concern and request to executives for necessary adjustment. In this way, the informal alignment between two endeavors takes shape in a bottom-up manner from employee participation, in contrast to task-technology fit based on a top-down arrangement.

In the task-technology fit model, the alignment construct embodies the aggregated influence from task characteristics and technology characteristics to predict task performance and technology use (Goodhue and Thompson 1995). This conceptualization of alignment as the joint between task and technology presumes that it is the necessary condition for both to work out. In empirical studies, task and technology characteristics are rarely included in the statistical modeling as they are not supposed to lead to the outcomes separately by themselves. The relative independence between GSCM and GIS, on the other hand, suggest that they have direct impacts on the outcome variables in terms of green innovation performances. Their informal alignment taps the synergistic effect as a third predictor that provides additional explanatory power.

Similar to GIS and GSCM endeavors, their consequences have multiple aspects. In addition to economic and operational performances related to the efficiency gains from green innovation, environmental and social performances pertain to its external impacts (Chiou et al. 2011; De Giovanni 2012). Together they correspond to the triple bottom lines of sustainability in terms of profits (i.e. economic and operational performances), people (i.e. social performance), and planet (i.e. environmental performance) (Savitz 2014). Compared with the traditional focus on profit, sustainable development and public image become more prominent for contemporary corporates. Prior discussions on GSCM and GIS are largely separated from each other in terms of their impacts on green innovation outcome (Rao and Holt 2005; Velte et al. 2008). It remains a question how GSCM and GIS together affect organizations in their pursuit of business goals and fulfillment of environmental responsibilities.

\section{Research Model}

Based on the premise of task-technology fit, user performances are enhanced when technologies facilitate tasks. Though most organizations implement GSCM and GIS separately, employees may engage in both if available for common purposes. Typically, their informal alignment takes shape when employees use GIS functions to support GSCM activities. As circumstantial evidence, organizations that are successful in GSCM have also implemented strong IT infrastructure (Boudreau et al. 2008; Erek et al. 2011). To accurately assess the synergistic effect between GSCM and GIS on green innovation outcome, the research model shown in Figure 1 hypothesizes their own relationships with organizational performances together with their alignment's. The relationships are not to be evaluated simultaneously but by stages in the order of hypothesis numbers (i.e. H1, H2, and H3). The sequence reflects how GSCM and GIS are implemented and integrated by most organizations: they usually carry out GSCM first for immediate changes, GIS next for enhanced results, and finally the integration between two for optimized outcome. Controlling for the influence of GSCM and GIS endeavors, this study estimates the effect of their alignment on each aspect of sustainability outcome. Such a systematic investigation yields insights that are unavailable from separate analyses on GSCM and GIS. 


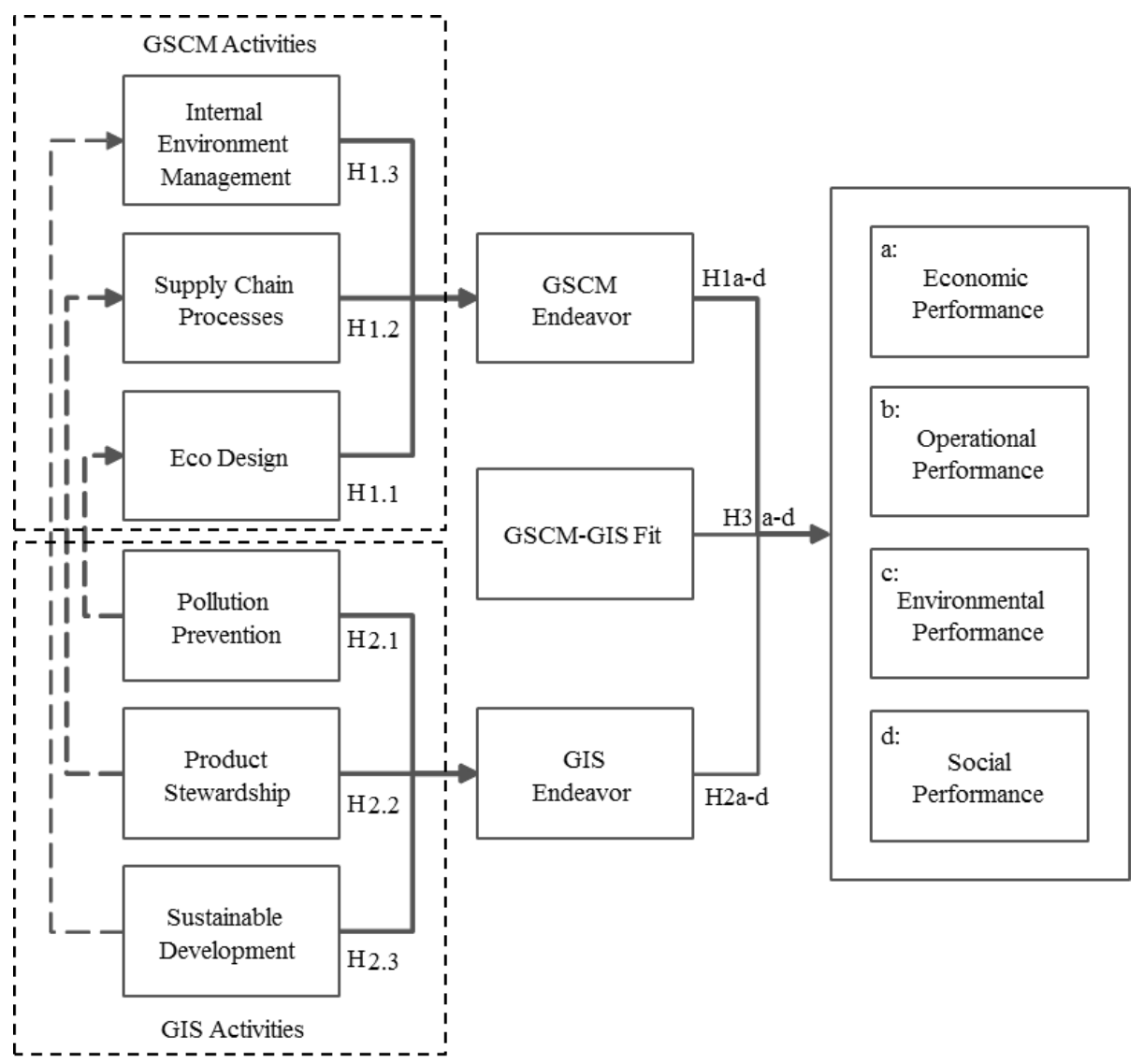

Fig. 1 Research Model

\subsection{GSCM Endeavour}

\subsubsection{Eco Design}

Eco-design concerns design concept and process that lead to environment-friendly production in terms of waste/emission reduction and energy conservation (Zhu et al. 2008a). It permeates various stages of a product lifecycle, including initial idea development, product design and testing, production, usage and recycling (GonzálezBenito and González-Benito 2005). Keeping the ecological consideration at the center, organizations are in the position to achieve the environmental goals through the adoption/development of cleaner production technologies (Zhang et al. 2013) and the collection of feedback from end users on products/services (Appelhanz et al. 2015).

The overall success of GSCM depends on how well different functionalities within an organization cooperate with each other and how well the organization collaborates with external suppliers and customers (Zhu and Sarkis 2006). The external relationships keep an organization updated on the requirement regarding its social and environmental responsibilities for necessary adjustment of internal operations (Azevedo et al. 2016). Such an information exchange facilitates close coordination among the internal functionalities and external partners of an organization on product planning, development, and evaluation (Fuchs 2008). The holistic approach ensures that GSCM endeavor is on the correct path to sustainability goal.

\section{H1.1: Eco design contributes to GSCM endeavor.}

\subsubsection{Supply Chain Processes}

The process view of GSCM breaks it into inbound logistics, production and outbound logistics stages, and how well the whole process is controlled and managed largely determines its success or failure (Lamming and Hampson 1996). Many corporates implement total quality management over the whole process of procurement, production, distribution, and recycling (Hines and Johns 2001). As supply chain processes involve internal and external stakeholders, it is essential to coordinate their joint effort (Luo et al. 2014). 
Concerning both inbound and outbound logistics, green procurement is identified as an important process for corporate sustainability (Min and Galle 1997). For instance, the acquirement and distribution of the products packaged with bio-degradable and recyclable materials effectively reduce waste and emission. In addition, green procurement also encourages suppliers to establish GSCM practices for better collaboration (Walton et al. 1998). Compared with inbound and outbound logistics, organizations have more direct control over manufacturing routines to make them more environment-friendly (Daugherty et al. 2005). For GSCM endeavor at large, therefore, good process management leads to expected results.

H1.2: Supply chain processes contribute to GSCM endeavor.

\subsubsection{Internal Environment Management}

Internal environment management refers to the spectrum of organizational policies, managerial controls and employee participation for the purpose of sustainable development (Zhu et al. 2008b). More specifically, it includes the commitment and support of managers and executives on green operations, cross-function and crossdepartment cooperation on energy conservation and environment protection, the establishment of environmental compliance and auditing programs, and so on. Thus, internal environment management provides necessary organizational support that is indispensable to the accomplishment of GSCM endeavor.

H1.3: Internal environment management contributes to GSCM endeavor.

In summary, GSCM endeavor comprises eco design, supply chain processes and internal environment management to save energy, reuse materials, and reduce wastes and emission in the whole supply chain. These activities not only yield positive ecological impacts, but also enhance economic performance by saving costs (Chiu and Hsieh 2016). Organizations that implement GSCM need to reengineer existing business processes, which improves operational performance. GSCM endeavor is also driven by the pressure from external stakeholders including clients/customers, governments, shareholders, nongovernmental organizations and communities (Dai et al. 2014; Kuei et al. 2015). Practices such as providing product recycling services to downstream customers and complying with governmental regulations concern the people aspect of triple bottom-lines and are conducive to corporate green image and social performance (De Giovanni 2012).

H1a: GSCM endeavor positively affects economic performance.

H1b: GSCM endeavor positively affects operational performance.

H1c: GSCM endeavor positively affects environmental performance.

H1d: GSCM endeavor positively affects social performance.

\subsection{GIS Endeavour}

\subsubsection{Pollution Prevention}

Pollution prevention refers to the use of information systems for the purpose of minimizing wastes and emission during production (Darnall et al. 2008). For instance, the use of computer aided design (CAD) and more recent 3-D printing technology may reduce the consumption of materials and energy in manufacturing significantly. Similar to GSCM's eco-design, pollution prevention directly aims at the ecological target of green innovation. It pertains to the ecological goal of GIS endeavor through the optimization of production for less environmental impact with technological facilitation.

\section{H2.1: Pollution prevention contributes to GIS endeavor.}

\subsubsection{Product Stewardship}

Product stewardship refers to the use of information systems to improve the efficiency in raw material acquisition, product distribution and product disassembly/remanufacturing (Gholami et al. 2013). For instance, justin-time manufacturing depends heavily on the use of inventory management systems to minimize the need for intermediate warehousing and handling. The streamlined operation not only saves money, but also reduces energy consumption and material waste. In this sense, product stewardship addresses the operational process of GIS endeavor, corresponding to GSCM's supply chain processes.

H2.2: Product stewardship contributes to GIS endeavor.

\subsubsection{Sustainable Development}


Sustainable development refers to the use of information systems to facilitate green operation and managerial control for better environmental compliance (Boudreau et al. 2008; Watson et al. 2010).

Teleconferencing and telecommuting are good examples that organizations accommodate more efficient and ecological ways for employees to work with the help of technologies. For monitoring and auditing energy and material consumption, organizations also implement new technology-enabled business routines. As a counterpart of GSCM's internal environment management, sustainable development is closely related to the organizational support of GIS endeavor.

H2.3: Sustainable development contributes to GIS endeavor.

The resource-based view of information systems suggests that organizations acquire, configure, deploy, and leverage IT resources to support business strategies and enhance value chain capabilities (Bharadwaj 2000). Accordingly, GIS can be viewed as an essential resource for organizations to promote green strategy by streamlining internal and external information flows. The resulted organizational changes, especially business process design and reengineering, not only enhance productivity and efficiency but also enable fast responses to the needs of customers and society for environment-friendly products and services (Bergenwall et al. 2012).

H2a: GIS endeavor positively affects economic performance.

H2b: GIS endeavor positively affects operational performance.

H2c: GIS endeavor positively affects social performance.

H2d: GIS endeavor positively affects environmental performance.

\subsection{GSCM-GIS Fit}

Extending the concept of task-technology fit to the organizational level, researchers suggest that how IT capability is aligned with organizational mission makes a difference in business effectiveness (Wilden et al. 2013; Dutot et al. 2014). Meanwhile, the implementation and usage of technologies is a mutual adaptation process with organizational changes (Leonard-Barton 1988). In the case of green innovation, GSCM comprises complex managerial activities indispensable from IT support (Ruppel 2004). For the same sustainability purpose, GIS provides the functions that are consistent with GSCM activities along the aforementioned dimensions of goal, process, and structure. Employee engagement in both endeavors facilitates green innovation through knowledge sharing and operation integration (Yang et al. 2015). The informal alignment between GSCM and GIS from the spontaneous and synergistic effort enhances different aspects of corporate sustainability.

H3a: GSCM-GIS fit positively affects economic performance.

H3b: GSCM-GIS fit positively affects operational performance.

H3c: GSCM-GIS fit positively affects social performance.

H3d: GSCM-GIS fit positively affects environmental performance.

\section{Methodology}

To test the research hypotheses, this study conducts a survey to gather observations from the managers in organizations that take the green innovation initiative. This section discusses the methodological issues including sample selection, questionnaire measures, and statistical analyses.

\subsection{Sample}

As the emerging industrial powerhouse, China faces the challenge to strike a balance between development and environment (Park et al. 2010). Since the new millennium, the country has significantly strengthened environmental legislation and regulation, and many organizations that fail to meet new emission and consumption standards have to close or phase out (Ying and Yue 2017). For businesses in different industries, sustainability is not just a buzzword but has a life-or-death implication. Thus, the target population of this study includes Chinese companies of which the operations involve supply chains and/or logistics.

Based on the mailing lists from the chambers of commerce at several big cities in China (Beijing, Shanghai, Guangzhou, Xi'an, Jinan), a pool of 450 organizations was obtained based on snowball and cluster sampling. About two thirds of the observations were collected with onsite interviews and the rest through online surveys with followup email reminders. There were a total of 356 responses, and the response rate was $79 \%$. Among the participants, 
311 reported that their organizations indeed used information systems for green purposes. Thus, the final valid responses accounted for $69 \%$ of total questionnaires distributed and $85 \%$ of all the responses collected. The nonresponse rate (i.e. $79 \%$ ) was close to valid response rate (i.e. $85 \%$ ), suggesting that many organizations chose not to answer the questionnaire mainly due to the fact that they had not implemented either GSCM or GIS yet. Thus such self-selection is likely to be the result of eligibility filtering rather than systematic non-response bias, which is to be assessed further below.

This study follows the recommended procedures to mitigate common method bias (Podsakoff et al. 2012). Among all the valid responses, $90 \%$ were collected from middle management (i.e. $57 \%$ operation-level managers and $33 \%$ department-level managers), and the rest from top management (i.e. 10\% executive-level managers). As most participants were the managers in supply-chain-related areas (e.g. sales, manufacturing, R\&D, logistics) and they were able to provide accurate information. During data collection, they were informed that there were no right or wrong answers, and their responses would be kept anonymous and confidential.

Table 1 reports the profile of participating organizations, which indicates a good mixture of industries, sizes and years in business. Just $15 \%$ of them were manufacturers, doubled by those from other traditional sectors including energy, real estate and transportation. The rest 55\% were from the emerging IT, service and other industries. A little bit less than $50 \%$ of organizations were small and medium businesses that had less than 500 employees, and another half were larger companies that had more than 500 employees (almost 15\%) and 1000 or more (almost 40\%). Almost 40\% of the organizations were in business for 10 to 20 years. Among the rest, about half were younger and the other older.

Table 1. Profiles of Organizations

\begin{tabular}{lcc}
\hline \hline \multicolumn{1}{c}{ Characteristics } & Number & $\%(\mathrm{~N}=311)$ \\
\hline Industry & & \\
Manufacturing & 45 & 14.5 \\
Energy & 41 & 13.2 \\
Real Estate & 37 & 11.9 \\
Transportation & 15 & 4.8 \\
IT & 65 & 20.9 \\
Service & 56 & 18.0 \\
Other & 49 & 15.8 \\
Not reported & 3 & 1.0 \\
Size (\# of employees) & & \\
1-49 & 35 & 11.3 \\
50-99 & 42 & 13.5 \\
100-499 & 69 & 22.2 \\
500-1000 & 40 & 12.9 \\
Above 1000 & 122 & 39.2 \\
Not reported & 3 & 1.0 \\
Years in business & & \\
$0-5$ & 38 & 12.2 \\
6-10 & 49 & 15.8 \\
11-15 & 73 & 23.5 \\
16-20 & 42 & 13.5 \\
Above 20 & 96 & 30.9 \\
Not reported & 13 & 4.2 \\
\hline & &
\end{tabular}


To further assess the aforementioned non-response bias, Chi-square tests were conducted to compare participating organization profiles (i.e. industry, years in business and size) across the onsite interview group (which had a higher response rate over 90\%) and online survey group (which had a lower response rate close to 60\%). None of the tests were statistically significant at the 0.05 level, indicating that the profile distributions of participating organizations were mostly independent from the data collection methods associated with different response rates. Thus non-response bias is not evident in the observations.

\subsection{Measurement}

The Appendix lists the Likert items adapted from previous studies. GSCM's eco-design, supply chain processes and internal environment management were measured with items adapted from Lee et al. (2012). Measures of GIS' pollution prevention, product stewardship and sustainable development were selected from Gholami et al. (2013) and Daugherty et al. (2005). The measurement of GSCM-GIS fit was based on the perceived task-technology fit scale of Lin and Huang (2008) as the informal alignment is based on employee spontaneous engagement in both green innovation endeavors. Environmental performance measures were adapted from Gholami et al. (2013) and Chiou et al. (2011). Economic performance was measured with the items developed by Daugherty et al. (2005). Operational performance items came from Green Jr et al. (2012) and Lee et al. (2012). The measurement of social performance was based on Turban and Greening (1997).

To elicit more accurate responses, the questionnaire included a list of common GSCM and GIS activities (identified from a literature review and refined with a pilot study) in the front for participants to check if each was carried out in their organizations. The inclusion of both objective and subjective items helps mitigate the common method bias associated with survey methodology (Podsakoff et al. 2012). The authors translated all measurement items into Chinese so that the questionnaires could be distributed to the organizations in China. Then a certified translation service translated them back to English. The back-translated questionnaires were reviewed by several native English speakers and none of them indicated difficulty to understand the questions. They also read the original English questionnaire and they did not see any significant deviations between two versions.

\subsection{Statistical Analyses}

Unlike the other constructs, GSCM Endeavor and GIS Endeavor comprise multiple dimensions. Each should be modeled as a first-order reflective and second-order formative construct (Petter et al. 2007). For validating first-order reflective measures, SPSS Amos is used in confirmatory factor analysis (CFA). The main statistical method to test research hypotheses is structural equation modeling based on partial least squares (PLS-SEM), which is able to accommodate multidimensional constructs (Wetzels et al. 2009; Hair Jr et al. 2014). The specific tool used in this study is SmartPLS3.2.7 program (Ringle et al. 2015). Similar to hierarchical regression analysis but involving latent constructs and mediating relationships, the explanatory variables were entered by stages in the order of GSCM, GIS and their fit. Such an incremental PLS-SEM approach controls the effects of previous variables to evaluate the additional explanatory power of later variables in terms of $R$-squared changes.

\section{Results}

Table 2 reports measurement validation results. All reliability coefficients were above 0.7 , indicating acceptable internal consistency. All the values of squared multiple correlation (SME) and average variance extracted (AVE) were also above 0.5. As the variance explained exceeds measurement error, convergent validity among the indicators of each construct was supported. In addition, discriminant validity among factors was supported as their highest correlation coefficient (i.e. 0.77) was smaller than the lowest square root of AVE (i.e. 0.83).

For a multidimensional construct like GSCM or GIS Effort in this study, any two of its dimensions are not supposed to be highly correlated with each other or they should be considered as one. Thus, the multicollinearity among eco design (ECO), supply chain processes (SCP) and internal environment management (IEM) for GSCM as well as pollution prevention (PP), product stewardship (PS) and sustainable development (SD) for GIS were assessed. None of the variance inflation factors (VIFs) were greater than 5 , indicating that the multicollinearity was not a concern (O'brien 2007). This result supports the validity of both multidimensional constructs as their components are distinguishable from each other.

To examine common method bias, this study conducted Harman's single-factor test with both exploratory factor analysis (EFA) and confirmatory factor analysis (CFA) (Podsakoff et al. 2003). The results dismissed a single source of variance: EFA revealed that the first factor accounted for less than one third (31.68\%) of the total variance, and CFA indicated that model fit deteriorated dramatically ( $\chi^{2}$ from 1410.20 to 9394.94 , and $\chi^{2} / d f$ from 1.95 to 
11.46) if all measurement items were loaded onto a single factor rather than their own constructs. Thus common method bias was not a concern.

Table 2. Measurement Validation

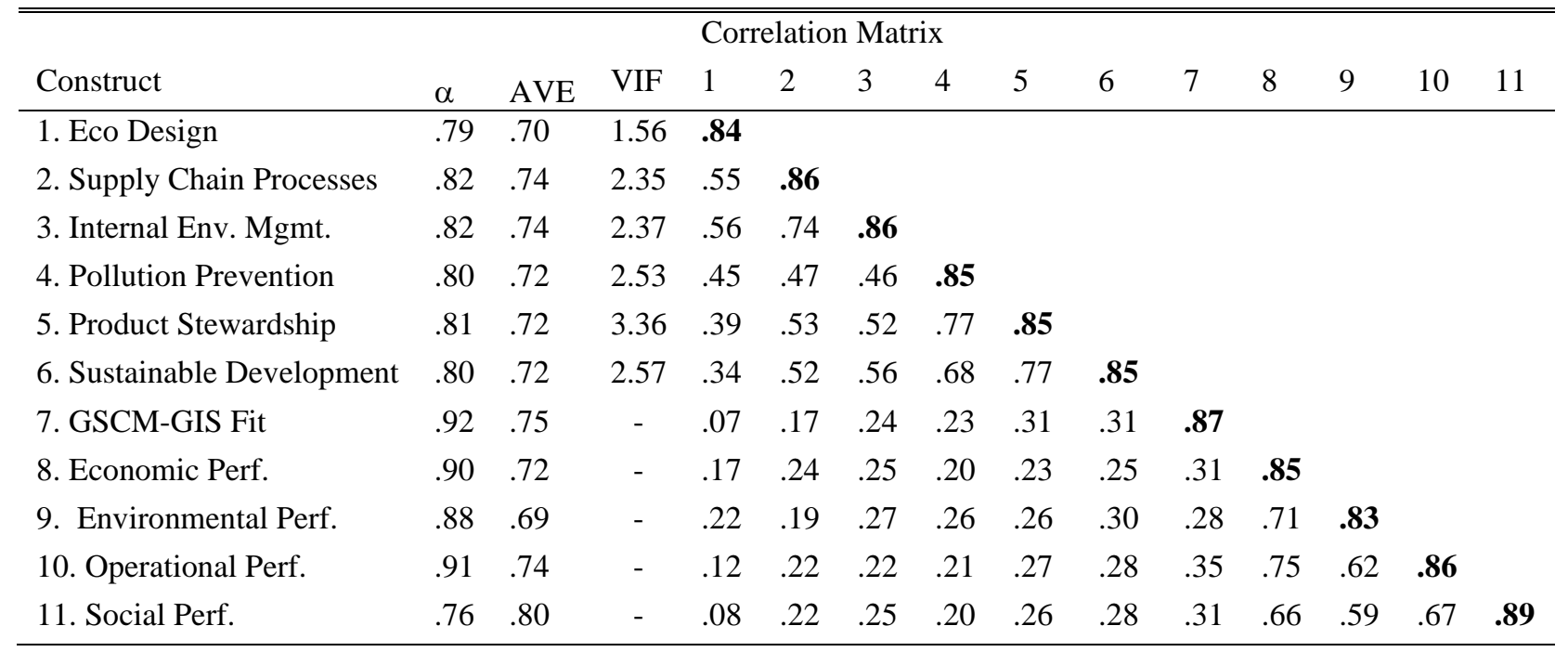

$\alpha$-Cronbach's alpha; AVE - average variance extracted; VIF - variance inflation factor. Bolded on the diagonal of correlation matrix are the square roots of AVEs.

Table 3 reports the results of PLS analyses. For each outcome variable, Stage 1 includes the GSCM variables, Stage 2 adds the GIS variables and Stage 3 enters GSCM-GIS fit. The total effect size is indicated by overall $R$-squared: when all explanatory variables were entered, they explained around $15 \%$ variation in performance variables. Most of the studies on the relationships between organizational innovations and performances reported similar levels between 0.1 and 0.2 (Rai et al. 2006; Damanpour et al. 2009). There are many other important factors that make differences in organizational performances, but the variables of interest included in this study were still able to contribute a significant proportion.

The additional explanatory power brought by a new variable entered is captured with $R$-squared change. Among GSCM, GIS and their fit, the alignment variable's effect size was the largest for the models of operational and social performances $(7.5 \%$ for $\mathrm{H} 3 \mathrm{~b}$ and $5.7 \%$ for $\mathrm{H} 3 \mathrm{~d}$ ), and the second largest for models of economic performance ( $6.0 \%$ for $\mathrm{H3a}, 0.9 \%$ short of GSCM's for H1a) and environmental performances $(3.8 \%$ for $\mathrm{H} 3 \mathrm{c}, 3.2 \%$ short of GSCM's for H1c). The effect size of GIS was the smallest for all models (between $1.3 \%$ and 3.4\% for H2ad), but its alignment with GSCM greatly enhanced green innovation outcome. Similarly, the average change of $R$ squared was 0.028 from Stage 1 to Stage 2 (47\% lift), and 0.0575 from Stage 2 to Stage 3 (66\% lift from Stage 2, total lift of $145 \%$ from Stage 1). The inclusion of GSCM-GIS fit significantly boosted the explanatory power, supporting the predictive validity of such an informal alignment.

Consistent with the explanatory power of GSCM-GIS fit, the standardized path coefficient estimates indicated that it had highly significant effects ( $p$-values < 0.01 ) on all performance variables. Obtained in Stage 3 controlling the effects of GSCM and GIS, these relatively accurate estimates confirm research hypotheses H3a through H3d. Similarly, Stage 2 tested GIS-related hypotheses controlling the effects of GSCM variables. All hypothesized relationships were found significant, mostly at the 0.01 level except for that related to economic performance ( $p$-value $<0.05$ ). The results supported the research hypotheses of $\mathrm{H} 2 \mathrm{a}$ through $\mathrm{H} 2 \mathrm{~d}$ regarding the effects of GIS Endeavor on performance variables, as well as $\mathrm{H} 2.1$ through $\mathrm{H} 2.3$ regarding the contributions of its different aspects. In Stage 1, all hypothesized relationships related to GSCM were found significant at the 0.01 level. This supported the research hypotheses of H1a through H1d regarding the effects of GSCM Endeavor on performance variables, as well as H1.1 through H1.3 regarding the contributions of its different aspects. 
Table 3. Hierarchical PLS Estimates for Models of Different Outcome Variables

\begin{tabular}{|c|c|c|c|c|c|c|c|c|c|c|c|c|}
\hline \multirow{2}{*}{$\begin{array}{l}\text { Performance } \\
R \text {-Squared }\end{array}$} & \multicolumn{3}{|c|}{ Economic } & \multicolumn{3}{|c|}{ Operational } & \multicolumn{3}{|c|}{ Environmental } & \multicolumn{3}{|c|}{ Social } \\
\hline & .069 & .049 & .070 & .048 & .082 & .083 & .102 & .081 & .142 & .158 & .140 & .138 \\
\hline H1:GSCM $\rightarrow$ Performance & $.263^{* * * *}$ & $.173^{* * * *}$ & $.166^{* * * *}$ & $.221^{* * *}$ & .076 & .074 & $.264^{* * * *}$ & $.127^{*}$ & $.129^{* *}$ & $.218^{* * * *}$ & .084 & .083 \\
\hline -H1.1: Eco Design $\rightarrow$ GSCM & $.339^{* * *}$ & $.338^{* * *}$ & $.338^{* * *}$ & $.337^{* * *}$ & $.337^{* * *}$ & $.336^{* * *}$ & $.344^{* * *}$ & $.344^{* * *}$ & $.344^{* * *}$ & $.333^{* * *}$ & $.332^{* * *}$ & $.333^{* * *}$ \\
\hline -H1.2: Supply Chain Processes $\rightarrow$ GSCM & $.406^{* * *}$ & $.406^{* * *}$ & $.407^{* * *}$ & $.408^{* * *}$ & $.408^{* * *}$ & $.408^{* * *}$ & $.399^{* * *}$ & $.400^{* * *}$ & $.399^{* * *}$ & $.408^{* * *}$ & $.408^{* * *}$ & $.408^{* * *}$ \\
\hline $\begin{array}{l}\text {-H1.3: Internal Environment } \\
\text { Management } \rightarrow \text { GSCM }\end{array}$ & $.409^{* * *}$ & $.409^{* * *}$ & $.409^{* * *}$ & $.409^{* * *}$ & $.409^{* * *}$ & $.409^{* * *}$ & $.411^{* * *}$ & $.411^{* * *}$ & $.411^{* * *}$ & $.413^{* * *}$ & $.413^{* * *}$ & $.413^{* * *}$ \\
\hline H2:GIS $\rightarrow$ Performance & & $.146^{* *}$ & .068 & & $.236^{* * *}$ & $.147^{* * *}$ & & $.226^{* * * *}$ & $.157^{* * * *}$ & & $.226^{* * * *}$ & $.145^{* *}$ \\
\hline -H2.1: Pollution Prevention $\rightarrow$ GIS & & $.359^{* * *}$ & $.359^{* * * *}$ & & $.357^{* * *}$ & $.357^{* * *}$ & & $.361^{* * *}$ & $.361^{* * *}$ & & $.357^{* * *}$ & $.357^{\text {**** }}$ \\
\hline$-\mathrm{H} 2.2$ : Product Stewardship $\rightarrow$ GIS & & $.378^{* * *}$ & $.378^{* * *}$ & & $.379^{* * *}$ & $.379^{* * *}$ & & $.376^{* * *}$ & $.376^{* * *}$ & & $.378^{* * *}$ & $.378^{* * *}$ \\
\hline -H2.3: Sustainable Development $\rightarrow$ GIS & & $.364^{* * *}$ & $.364^{* * *}$ & & $.365^{* * *}$ & $.365^{* * *}$ & & $.364^{* * *}$ & $.364^{* * *}$ & & $.365^{* * *}$ & $.365^{* * *}$ \\
\hline H3:GSCM-GIS Fit $\rightarrow$ Performance & & & $.263^{* * * *}$ & & & $.288^{* * * *}$ & & & $.209^{* * * *}$ & & & $.254^{* * * *}$ \\
\hline
\end{tabular}

Note: ${ }^{*}$ - Significant at 0.1 level; ${ }^{* *}$ - Significant at 0.05 level; ${ }^{* * *}$ - Significant at 0.01 level. The bold texts are related to the testing of main hypotheses. GSCM green supply chain management; GIS - green information systems. 


\section{Discussions}

Whereas all research hypotheses were supported when the variables in question were first entered in the hierarchical analysis, the significance of some previously entered variables diminished when other variables were included. With the entrance of GIS, the effects of GSCM on operational performance, environmental performance and social performance reduced from being highly significant ( $p$-values $<0.01)$ to not significant ( $p$-value $>0.05)$, marginally significant $(p$-value $<0.1)$, and not significant $(p$-value $>$ $0.05)$, respectively. By supporting GSCM, GIS explained the proportion of variance in the outcome variables previously accounted for. Similarly, when GSCM-GIS fit was entered, the relationships between GIS and all four performance variables weakened. In particular, the effects of GIS on economic performance and social performance changed from significant $(p$-value $<0.05)$ to not significant $(p$-value > 0.05 ) and from highly significant $(p$-value $<0.01)$ to significant $(p$-value $<0.05)$ respectively. Common for control variables, such an effect diminishment supports the incremental approach to assess the informal alignment between GSCM and GIS as they are controlled for their synergy. Compared with the effects of GSCM Effort and GIS Effort on organizational performances, each of their dimensions remained highly significant across three stages. The results indicate that the two multidimensional constructs have relative stable structures, supporting their construct validity.

The inclusion of economic, operational, environmental and social performances allows the comparison of different impacts that GSCM endeavor, GIS endeavor and GSCM-GIS fit have on each of them. The changes in the $R$-squared values across hierarchical models indicated that the inclusion of GIS and its alignment with GSCM yielded more explanatory power on operational performance and economic performance than on social performance and environmental performance. The performance measures correspond to the three bottom-lines of sustainability in terms of profitability, people, and planet. The finding is consistent with the widely accepted view that the use of information technology enhances the efficiency of organizational operations, leading to better economic outcomes. Of course, profitability is a more direct concern to organizations than people and planet that involve all kinds of extrinsic factors (e.g. government policy and regulation). Nevertheless, many organizations see the market opportunity of enhancing the green images of their brands and products through the communication of corporate social responsibility (Testa et al. 2016). The compliance to the requirements of environmental protection and sustainable development often leads to positive social recognition, a competitive advantage in the long run.

A closer look suggests that the supply chain processes (SCP) and internal environment management (IEM) aspects of GSCM have greater impacts on organizational performances than eco-design (ECO). SCP and IEM typically require the redesign and reengineering of managerial structure and process yet ECO focuses mainly on individual products. Similarly, the results suggest that the product stewardship (PS) and sustainable development (SD) components of GIS are more influential than pollution prevention (PP) on organizational performances. This finding provides circumstantial evidence for the corresponding relationships between GSCM aspects and GIS components (i.e. SCP vs. PS, IEM vs. SD, ECO vs. PP), which reveal the mechanism of how the alignment forms. More importantly, they suggest that organizations should pay more attention to the SCP and IEM aspects of GSCM and corresponding PS and SD components of GIS as they may involve deeper organizational changes than ECO and PP.

\section{Conclusion and Implications}

From an informal alignment perspective, this study examines the synergy between efficiencyoriented GSCM and technology-driven GIS on corporate sustainability. In particular, it hypothesizes that GSCM-GIS fit supplement the main effects of the two green innovation endeavors on organizational profitability in terms of economic and operational performances as well as social responsibility in terms of environmental and social performances. The relationships are tested with the observations collected from different organizations using a hierarchical PLS analysis. The results confirm all research hypotheses and support the conceptualization of informal alignment from the spontaneous engagement of employees (especially middle management) in both GSCM and GIS activities. The findings provide researchers and practitioners helpful insights on the synergy between GSCM and GIS and best practices to optimize their impacts on corporate sustainability.

This study contributes to the green innovation literature by revealing the potential synergy between the efficiency-oriented GSCM and technology-driven GIS endeavors. It extends the regular conceptualization of technology-task fit to the informal alignment between GSCM and GIS considering 
their relative independence rather than assuming interdependence. Similar to the role that weak ties play in information transmission through social networks (Granovetter 1983), informal alignment accounts for the extensive technological facilitation in green innovation.

Most empirical studies based on task-technology fit use the construct to predict user performance without including task and technology characteristics in actual modeling due to their close bonding from the formal alignment, that is: neither task nor technology is conducive to performance by themselves unless they align with each other. But this is not the case for informal alignment where its two sides may independently affect outcome variables. This study models GSCM-GIS fit as a third predictor along with the two primary endeavors to explain each aspect of green innovation outcome, and evaluates the synergistic effect with incremental PLS-SEM, which combines structural equation modeling with hierarchical regression. The quantitative assessment sheds light on the contribution of such an informal alignment on top of green innovation endeavors. Separately, GSCM and GIS are still conducive to corporate sustainability, but their fit serves as the catalyst to optimize their impacts, leading to a one-plusone-greater-than-two effect.

The findings yield useful practical insights as well. The synergy between GSCM and GIS assures organizations of implementing both and engaging employees in them. Although each alone is still helpful, the overall effectiveness is maximized when the two endeavors are closely knitted with each other in various aspects of business operations. Most corporates start with efficiency-oriented GSCM as the effort pays off directly with cost saving. To stay on the cutting edge of green innovation for enduring competitive advantages, however, it is necessary to embrace GIS technologies as they emerge. Such a technologydriven initiative creates the opportunity for employees to try out new technological functions for improving business routines. Managers should encourage such spontaneity and creativity to facilitate the informal alignment between GSCM and GIS.

Compared with the formal alignment between task and technology from the top-down arrangement, the informal alignment from the bottom-up participation is conducive to optimal green innovation effectiveness. To keep the momentum and dynamics for GSCM-GIS fit adjustment, management needs to provide necessary incentive and guidance for employees to engage in green innovation. For instance, organizations may host seminars to involve people from different departments in the exploration of emerging technologies for sustainability purposes. For those who come up with good ideas and even implement them in work, there will be rewards in forms of bonus and promotion. In this way, employees of various backgrounds and skills are motivated to find out ways to align GSCM and GIS in their daily routines. Over time, this cultivates an organizational culture that encourages green innovation through open communication and collaboration.

For the long-term success of green innovation, managers and employees at different levels need to work closely together in evaluating and adjusting GSCM-GIS fit. The assessment of such an informal alignment can be based on the methods demonstrated in this study. When employees perceive a low degree of alignment between two endeavors or it does not provide a significant boost to their performances, managers are prompted to figure out the reasons and address the issues. If the lack of technical skills prevents people from engaging in GSCM and/or GIS endeavors, for instance, an organization can provide more training opportunities and helpdesk supports. To facilitate employee communication and feedback, the management may establish a dedicated platform (e.g. discussion forum, social media) for green innovation.

This study is limited in the fact that all the observations were collected from a single country. China is the largest emerging economy in which organizations face both developmental and environmental pressures. Yet organizations in other countries may face some unique challenges of corporate sustainability due to different cultural, legal, and economic environments. Thus the single-country sample weakens the generalizability of specific findings. Future studies may collect observations from multiple countries and include relevant nation-level variables in analyses. 


\section{References}

Andersen, M., \& Skjoett-Larsen, T. (2009). Corporate social responsibility in global supply chains. Supply Chain Management: An International Journal, 14(2), 75-86.

Appelhanz, S., Osburg, V.-S., Toporowski, W., \& Schumann, M. (2015). Traceability system for capturing, processing and providing consumer-relevant information about wood products: system solution and its economic feasibility. Journal of Cleaner Production, 110, 132-148.

Azevedo, S. G., Carvalho, H., Ferreira, L. M., \& Matias, J. C. (2016). A proposed framework to assess upstream supply chain sustainability. Environment, Development and Sustainability, 1-21.

Bergenwall, A. L., Chen, C., \& White, R. E. (2012). TPS's process design in American automotive plants and its effects on the triple bottom line and sustainability. International Journal of Production Economics, 140(1), 374-384.

Bharadwaj, A. S. (2000). A resource-based perspective on information technology capability and firm performance: an empirical investigation. MIS Quarterly, 169-196.

Boudreau, M.-C., Chen, A., \& Huber, M. (2008). Green IS: Building sustainable business practices. Information systems: A global text. University of Georgia, 1-17.

Brundtland, G. H. (1987). Report of the World Commission on environment and development:" our common future.": United Nations.

Chen, A. J., Watson, R. T., Boudreau, M.-C., \& Karahanna, E. (2011). An institutional perspective on the adoption of Green IS \& IT. Australasian Journal of Information Systems, 17(1), 23-45.

Chiabai, A., Rübbelke, D., \& Maurer, L. (2013). ICT applications in the research into environmental sustainability: a user preferences approach. Environment, Development and Sustainability, 15(1), $81-100$

Chiou, T.-Y., Chan, H. K., Lettice, F., \& Chung, S. H. (2011). The influence of greening the suppliers and green innovation on environmental performance and competitive advantage in Taiwan. Transportation Research Part E: Logistics and Transportation Review, 47(6), 822-836.

Chiu, J.-Z., \& Hsieh, C.-C. (2016). The impact of restaurants' green supply chain practices on firm performance. Sustainability, 8(1), 42.

Chofreh, A. G., Goni, F. A., Shaharoun, A. M., Ismail, S., \& Klemeš, J. J. (2014). Sustainable enterprise resource planning: imperatives and research directions. Journal of Cleaner Production, 71, 139147.

Dai, J., Montabon, F. L., \& Cantor, D. E. (2014). Linking rival and stakeholder pressure to green supply management: Mediating role of top management support. Transportation Research Part E: Logistics and Transportation Review, 71, 173-187.

Damanpour, F., Walker, R. M., \& Avellaneda, C. N. (2009). Combinative effects of innovation types and organizational performance: A longitudinal study of service organizations. Journal of Management Studies, 46(4), 650-675.

Darnall, N., Jolley, G. J., \& Handfield, R. (2008). Environmental management systems and green supply chain management: complements for sustainability? Business Strategy and the Environment, 17(1), 30-45.

Daugherty, P. J., Richey, R. G., Genchev, S. E., \& Chen, H. (2005). Reverse logistics: superior performance through focused resource commitments to information technology. Transportation Research Part E: Logistics and Transportation Review, 41(2), 77-92.

Davenport, T. H. (2013). Process innovation: reengineering work through information technology: Harvard Business Press.

De Giovanni, P. (2012). Do internal and external environmental management contribute to the triple bottom line? International Journal of Operations \& Production Management, 32(3), 265-290.

Dedrick, J. L. (2010). Green IS: Concepts and issues for information systems research. CAIS, $27(1), 11$.

Dutot, V., Bergeron, F., \& Raymond, L. (2014). Information management for the internationalization of SMEs: An exploratory study based on a strategic alignment perspective. International Journal of Information Management, 34(5), 672-681.

Dymoke-Bradshaw, C., \& Cox, B. (2005). Developing organization-technology fit: the role of evaluation in IS innovation projects. Electronic Journal of Information Systems Evaluation, 4(1).

Erek, K., Loeser, F., Schmidt, N.-H., Zarnekow, R., \& Kolbe, L. M. Green It Strategies: A Case StudyBased Framework For Aligning Green It With Competitive Environmental Strategies. In PACIS, 2011 (pp. 59) 
Fuchs, C. (2008). The implications of new information and communication technologies for sustainability. Environment, Development and Sustainability, 10(3), 291-309.

Fuller, R. M., \& Dennis, A. R. (2009). Does fit matter? The impact of task-technology fit and appropriation on team performance in repeated tasks. Information Systems Research, 20(1), 2-17.

Gholami, R., Sulaiman, A. B., Ramayah, T., \& Molla, A. (2013). Senior managers' perception on green information systems (IS) adoption and environmental performance: Results from a field survey. Information \& Management, 50(7), 431-438.

González-Benito, J., \& González-Benito, Ó. (2005). Environmental proactivity and business performance: an empirical analysis. Omega, 33(1), 1-15.

Goodhue, D. L., \& Thompson, R. L. (1995). Task-technology fit and individual performance. MIS Quarterly, 19(2), 213-236.

Granovetter, M. (1983). The strength of weak ties: A network theory revisited. Sociological theory, 1, 201233.

Green Jr, K. W., Zelbst, P. J., Meacham, J., \& Bhadauria, V. S. (2012). Green supply chain management practices: impact on performance. Supply Chain Management: An International Journal, 17(3), 290-305.

Grøgaard, B. (2012). Alignment of strategy and structure in international firms: An empirical examination. International Business Review, 21(3), 397-407.

Guth, W. D., \& MacMillan, I. C. (1986). Strategy implementation versus middle management self interest. Strategic management journal, 7(4), 313-327.

Hair Jr, J. F., Hult, G. T. M., Ringle, C., \& Sarstedt, M. (2014). A primer on partial least squares structural equation modeling (PLS-SEM). Thousand Oaks, CA: Sage Publications.

Heyden, M. L., Fourné, S. P., Koene, B. A., Werkman, R., \& Ansari, S. S. (2017). Rethinking 'top down' and 'bottom - up' roles of top and middle managers in organizational change: Implications for employee support. Journal of Management Studies, 54(7), 961-985.

Hines, F., \& Johns, R. Environmental supply chain management: evaluating the use of environmental mentoring through supply chain. In greening of industry network conference, Bangkok, 2001

Jordan, E., \& Tricker, B. (1995). Information strategy: alignment with organization structure. The Journal of Strategic Information Systems, 4(4), 357-382.

Kuei, C.-h., Madu, C. N., Chow, W. S., \& Chen, Y. (2015). Determinants and associated performance improvement of green supply chain management in China. Journal of Cleaner Production, 95, 163-173.

Lamming, R., \& Hampson, J. (1996). The environment as a supply chain management issue. British Journal of Management, 7(s1).

Lee, S. M., Tae Kim, S., \& Choi, D. (2012). Green supply chain management and organizational performance. Industrial Management \& Data Systems, 112(8), 1148-1180.

Legarth, J. B. (2001). Internet assisted environmental purchasing. Corporate Environmental Strategy, 8(3), 269-274.

Leidner, D., Milovich, M., \& Preston, D. (2017). Rethinking IS Strategic Alignment: A Middle Management Perspective.

Leonard-Barton, D. (1988). Implementation as mutual adaptation of technology and organization. Research policy, 17(5), 251-267.

Lin, T.-C., \& Huang, C.-C. (2008). Understanding knowledge management system usage antecedents: An integration of social cognitive theory and task technology fit. Information \& Management, 45(6), 410-417.

Loos, P., Nebel, W., Marx Gómez, J., Hasan, H., Watson, R. T., vom Brocke, J., et al. (2011). Green IT: a matter of business and information systems engineering? Business \& Information Systems Engineering, 3(4), 245-252.

Luo, J., Chong, A. Y.-L., Ngai, E. W., \& Liu, M. J. (2014). Green Supply Chain Collaboration implementation in China: The mediating role of guanxi. Transportation Research Part E: Logistics and Transportation Review, 71, 98-110.

Melville, N. P. (2010). Information systems innovation for environmental sustainability. MIS Quarterly, $34(1), 1-21$.

Min, H., \& Galle, W. P. (1997). Green purchasing strategies: trends and implications. Journal of Supply Chain Management, 33(2), 10-17. 
Muduli, K., \& Barve, A. (2013). Sustainable development practices in mining sector: a GSCM approach. International Journal of Environment and Sustainable Development, 12(3), 222-243.

Murugesan, S. (2008). Harnessing green IT: Principles and practices. IT Professional, 10(1), 24-33.

O'brien, R. M. (2007). A caution regarding rules of thumb for variance inflation factors. Quality \& Quantity, 41(5), 673-690.

OECD (2010). Eco-innovation in industry: Enabling green growth. Paris, France: OECD (Organisation for Economic Co-operation Development) Publishing.

Ozturk, A., Umit, K., Medeni, I. T., Ucuncu, B., Caylan, M., Akba, F., et al. (2011). Green ICT (Information and Communication Technologies): a review of academic and practitioner perspectives. International Journal of eBusiness and eGovernment Studies, 3(1), 1-16.

Park, J., Sarkis, J., \& Wu, Z. (2010). Creating integrated business and environmental value within the context of China's circular economy and ecological modernization. Journal of Cleaner Production, 18(15), 1494-1501.

Petter, S., Straub, D., \& Rai, A. (2007). Specifying formative constructs in information systems research. MIS Quarterly, 623-656.

Podsakoff, P. M., MacKenzie, S. B., Lee, J.-Y., \& Podsakoff, N. P. (2003). Common method biases in behavioral research: a critical review of the literature and recommended remedies. Journal of Applied Psychology, 88(5), 879-903.

Podsakoff, P. M., MacKenzie, S. B., \& Podsakoff, N. P. (2012). Sources of method bias in social science research and recommendations on how to control it. Annual review of psychology, 63, 539-569.

Porter, M., \& Kramer, M. (2006). Strategy and society: the link between corporate social responsibility and competitive advantage. Harvard Business Review, 84(12), 78-92.

Rai, A., Patnayakuni, R., \& Seth, N. (2006). Firm performance impacts of digitally enabled supply chain integration capabilities. MIS Quarterly, 225-246.

Rao, P., \& Holt, D. (2005). Do green supply chains lead to competitiveness and economic performance? International Journal of Operations \& Production Management, 25(9), 898-916.

Ringle, C. M., Wende, S., \& Becker, J.-M. (2015). SmartPLS 3. Boenningstedt: SmartPLS GmbH.

Roettgers, F. (2011). Going green together: how to align employees with green strategies: Environmental Pioneers.

Ruppel, C. (2004). An information systems perspective of supply chain tool compatibility: the roles of technology fit and relationships. Business Process Management Journal, 10(3), 311-324.

Savitz, A. (2014). The triple bottom line: how today's best-run companies are achieving economic, social and environmental success-and how you can too: John Wiley \& Sons.

Seuring, S., \& Müller, M. (2008). From a literature review to a conceptual framework for sustainable supply chain management. Journal of Cleaner Production, 16(15), 1699-1710.

Srivastava, S. K. (2007). Green supply - chain management: a state - of - the - art literature review. International journal of management reviews, 9(1), 53-80.

Strong, D. M., \& Volkoff, O. (2010). Understanding Organization—Enterprise System Fit: A Path to Theorizing the Information Technology Artifact. MIS Quarterly, 731-756.

Testa, F., Grappio, P., Gusmerotti, N. M., Iraldo, F., \& Frey, M. (2016). Examining green public procurement using content analysis: existing difficulties for procurers and useful recommendations. Environment, Development and Sustainability, 18(1), 197-219.

Testa, F., \& Iraldo, F. (2010). Shadows and lights of GSCM (Green Supply Chain Management): determinants and effects of these practices based on a multi-national study. Journal of Cleaner Production, 18(10-11), 953-962.

Tseng, M.-L., \& Chiu, A. S. (2013). Evaluating firm's green supply chain management in linguistic preferences. Journal of Cleaner Production, 40, 22-31.

Turban, D. B., \& Greening, D. W. (1997). Corporate social performance and organizational attractiveness to prospective employees. Academy of management Journal, 40(3), 658-672.

Vachon, S., \& Klassen, R. D. (2006). Extending green practices across the supply chain: the impact of upstream and downstream integration. International Journal of Operations \& Production Management, 26(7), 795-821.

Velte, T., Velte, A., \& Elsenpeter, R. C. (2008). Green IT: reduce your information system's environmental impact while adding to the bottom line: McGraw-Hill, Inc.

Walton, S. V., Handfield, R. B., \& Melnyk, S. A. (1998). The green supply chain: integrating suppliers into environmental management processes. Journal of Supply Chain Management, 34(1), 2-11. 
Watson, R. T., Boudreau, M.-C., \& Chen, A. J. (2010). Information systems and environmentally sustainable development: energy informatics and new directions for the IS community. MIS Quarterly, 23-38.

Wetzels, M., Odekerken-Schröder, G., \& Van Oppen, C. (2009). Using PLS path modeling for assessing hierarchical construct models: Guidelines and empirical illustration. MIS Quarterly, 177-195.

Wilden, R., Gudergan, S. P., Nielsen, B. B., \& Lings, I. (2013). Dynamic capabilities and performance: strategy, structure and environment. Long Range Planning, 46(1), 72-96.

Yang, J., Han, Q., Zhou, J., \& Yuan, C. (2015). The influence of environmental management practices and supply chain integration on technological innovation performance-Evidence from China's manufacturing industry. Sustainability, 7(11), 15342-15361.

Ying, Q., \& Yue, L. (2017). Evaluating the low-carbon development of urban China. Environment, Development and Sustainability, 19(3), 939-953.

Zhang, B., Yang, S., \& Bi, J. (2013). Enterprises' willingness to adopt/develop cleaner production technologies: an empirical study in Changshu, China. Journal of Cleaner Production, 40, 62-70.

Zhu, Q., \& Sarkis, J. (2006). An inter-sectoral comparison of green supply chain management in China: drivers and practices. Journal of Cleaner Production, 14(5), 472-486.

Zhu, Q., Sarkis, J., Cordeiro, J. J., \& Lai, K.-H. (2008a). Firm-level correlates of emergent green supply chain management practices in the Chinese context. Omega, 36(4), 577-591.

Zhu, Q., Sarkis, J., \& Lai, K.-h. (2007). Green supply chain management: pressures, practices and performance within the Chinese automobile industry. Journal of Cleaner Production, 15(11), 1041-1052.

Zhu, Q., Sarkis, J., \& Lai, K.-h. (2008b). Confirmation of a measurement model for green supply chain management practices implementation. International Journal of Production Economics, 111(2), 261-273.

Zhu, Q., Sarkis, J., \& Lai, K.-h. (2012). Green supply chain management innovation diffusion and its relationship to organizational improvement: An ecological modernization perspective. Journal of Engineering and Technology Management, 29(1), 168-185.

Zsidisin, G. A., \& Siferd, S. P. (2001). Environmental purchasing: a framework for theory development. European Journal of Purchasing \& Supply Management, 7(1), 61-73. 


\section{Appendix: Measurement Items}

1. Green supply chain management (GSCM)

We utilize green supply chain management to...

\subsection{Eco design}

...reduce material/energy consumptions.

...reuse, recycle, and recover materials.

...reduce the use of hazardous/toxic materials.

1.2 Supply chain processes

...collaborate with suppliers for environmental objectives.

...collaborate with customers for green delivery.

...facilitate products disassembly and remanufacturing.

1.3 Internal environment management

...enhance cross-functional cooperation for environmental improvements.

...obtain management commitment and support for green operations.

...implement environmental compliance and auditing programs.

2. Green information systems (GIS)

We utilize green information systems to...

2.1 Pollution prevention

...reduce overall consumption and emissions.

...reduce overall waste.

...reduce overall use of hazardous and toxic materials.

2.2 Product stewardship

...make material sourcing and acquisition more environmentally friendly.

...make product distribution and delivery more environmentally friendly.

...make product disassembly and remanufacturing routings more environmentally friendly.

2.3 Sustainable development

...facilitate green operations across the organization.

...facilitate management support and control for sustainable development.

...facilitate environmental compliance and auditing.

\section{GSCM-GIS fit}

How we use green information systems ...

....is adequate to green supply chain management.

...is appropriate for green supply chain management.

...is compatible with green supply chain management.

...makes green supply chain management easy.

...fits green supply chain management in general.

4. Green innovation outcome 
4.1 Economic performance is enhanced in terms of:

...investment recovery

...cost containment

...profitability

...labor productivity

...inventory reduction

4.2 Operational performance is enhanced in terms of:

...product delivery

...product quality

...capacity utilization

...cycle time reduction

...customer service

4.3 Environmental performance is enhanced in terms of:

...material reuse

...environmental compliance

...environment preservation

...reduction of hazardous wastes and emissions

...reduction of resource consumptions (e.g. energy, water)

4.4 Social performance is enhanced in terms of:

...product liability and safety

...community outreach (e.g. education and charitable giving) 